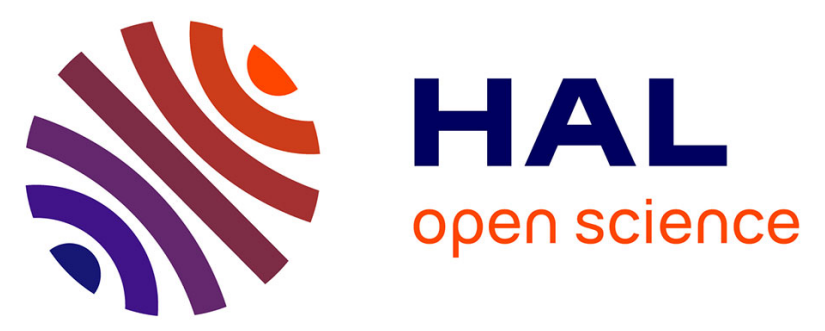

\title{
Motivations and Emotions in Social Media: Explaining Users' Satisfaction with FsQCA
}

Ilias O. Pappas, Sofia Papavlasopoulou, Panos E. Kourouthanassis, Patrick Mikalef, Michail N. Giannakos

\section{- To cite this version:}

Ilias O. Pappas, Sofia Papavlasopoulou, Panos E. Kourouthanassis, Patrick Mikalef, Michail N. Giannakos. Motivations and Emotions in Social Media: Explaining Users' Satisfaction with FsQCA. 16th Conference on e-Business, e-Services and e-Society (I3E), Nov 2017, Delhi, India. pp.375-387, 10.1007/978-3-319-68557-1_33. hal-01768509

\section{HAL Id: hal-01768509 \\ https://hal.inria.fr/hal-01768509}

Submitted on 17 Apr 2018

HAL is a multi-disciplinary open access archive for the deposit and dissemination of scientific research documents, whether they are published or not. The documents may come from teaching and research institutions in France or abroad, or from public or private research centers.
L'archive ouverte pluridisciplinaire HAL, est destinée au dépôt et à la diffusion de documents scientifiques de niveau recherche, publiés ou non, émanant des établissements d'enseignement et de recherche français ou étrangers, des laboratoires publics ou privés. 


\title{
Motivations and Emotions in Social Media: Explaining Users' Satisfaction with fsQCA
}

\author{
Ilias O. Pappas ${ }^{1}$, Sofia Papavlasopoulou ${ }^{1}$, Panos E. Kourouthanassis ${ }^{2}$, Patrick \\ Mikalef $^{1}$ and Michail N. Giannakos ${ }^{1}$ \\ ${ }^{1}$ Norwegian University of Science and Technology (NTNU), Trondheim, Norway \\ ${ }^{2}$ Ionian University, Corfu, Greece \\ \{ ilpappas, spapav, patrick.mikalef, michailg \} @ ntnu.no \\ pkoureionio.gr
}

\begin{abstract}
This study aims to explain how motivations and emotions combine to influence users' satisfaction with social media. Motivations are decomposed into four attributes, entertainment, information, social-psychological, and convenience, while emotions are divided into their two main categories, that is positive and negative emotions. In order to examine the interplay of these factors and their combined effect on satisfaction, a conceptual model is developed, and validated on a data sample of 582 social media users, through fuzzy-set qualitative comparative analysis (fsQCA). The findings indicate eight configurations that lead to high satisfaction, which show the importance of high convenience, followed by entertainment and information in being satisfied with social media, while emotions and social-psychological factors are less important. This study contributes in social media literature by identifying specific patterns of users for whom these factors are important and influence greatly their satisfaction.
\end{abstract}

Keywords: Social Media, Motivation, Emotions, FsQCA.

\section{$1 \quad$ Introduction}

Social media have intruded on peoples' lives and is a main computer activity. The main characteristic of social media is that they are highly experiential media and their value depends on users' adoption through interaction. Many studies in the area focus on systems' acceptance and satisfaction from their use, through technical and interface characteristics $[1,2]$. We suggest a different approach to satisfaction focusing on internal factors influencing the use of social media. As users' needs and motivations are not independent from the system they are using [3], we view users as individuals with motivations and emotions, which influence their satisfaction with social media use.

In the context of online services, affective states and their influence in behavior has been examined widely [4-6]. Emotions, like enjoyment and pleasure, may increase users' levels of satisfaction with online services [7]. Additionally, during the interaction with social media, different emotions are developed [8] affecting users' behavior and satisfaction [9]. Nonetheless, studies mainly focus on specific emotions, thus a holistic 
approach to the examination of emotions is needed. Here, we argue that it is needed to explore the role of motivations and emotions on increasing users' satisfaction, as the latter is a main antecedent of repeated behavior, on which social media adoption is based. As social media evolve and new types appear continuously, it is needed to understand factors that will lead to satisfied users, and by extension to loyal users.

Previous studies in the area of social media examine various ways influencing users' satisfaction or behaviour, identifying users' motivations, such as entertainment, information, social-psychological, convenience $[2,10]$, and various types emotions as important in influencing satisfaction or behaviour [7]. There is a lack of theories in the area and, mainly, empirical studies that examine the combined effects of the aforementioned factors. Users with different motivations and emotions, might not be represented from the one-model-fits-all produced from the traditional variance based approaches. Such traditional approaches (e.g., multiple regression analysis, structural equation modelling) assume that relations among variables are symmetric and offer one single best solution that explains the outcome. However, a sample includes variables with asymmetric relationships among each other, not identifiable by traditional approaches [11]. Thus, multiple configurations of the examined variables lead to multiple solutions explaining the same result, while representing overall a larger part of the sample.

In this study, we build on complexity theory and configuration theory in order to identify the different causal patterns of factors that users' satisfaction with social media. To this end, we employ a fuzzy-set qualitative comparative analysis (fsQCA) [12] to explain how motivations and emotions lead to high satisfaction with social media. The findings identify multiple, different, and equally effective combinations of motivations and emotions that are able to explain high satisfaction. The paper contributes to existing literature in two main ways. First, it provides empirical evidence on the importance of motivations in satisfied customers, and second, it examines the combined influence of motivations (i.e., entertainment, information, social-psychological, convenience) and emotions (i.e., positive and negative emotions) on satisfaction with social media.

\section{Background and conceptual model}

\subsection{Motivations when using social media}

People using social media have various needs and their motivations may differ, influence their actions, and their fulfillment is expected to increase their satisfaction. This is inherent in the uses and gratification theory (UGT) which, in the context of social media, suggests that the use of social media is based on and motivated by users' inner needs [13]. Such motivations include socializing, entertainment, information, psychological, and hedonic motivation $[2,9,10]$, and are linked with the benefits that social media may offer to their users by covering their needs [10]. People use social media to find their friends, communicate with them in a convenient way, develop a feel of belongingness, encouragement and companionship from both existing social relationships, but also create new relationships based on similar interests and preferences [2]. Also, individuals may use social media to seek information, on multiple occasions, 
from news to travelling information. Also, individuals may seek social and psychological benefits through social media, which may be gained as people continuously use social media [10]. Furthermore, users are likely to use social media and visit online communities because they feel they are fun or amusing [14], suggesting that emotions play in important part both in their satisfaction and their overall behaviour. The convenience and entertainment that social media offer, for example by being pleasing and easy to use [15], will increase users' intention to adopt them. The latter is directly influenced by users' satisfaction [16], highlighting its importance in forming users' motivation in social media. To improve our understanding of social media usage and explain individuals' satisfaction with them further work is needed to provide an integrated view of social media by employing new methods that are able to give more insight into the area.

\subsection{Emotions and social media satisfaction}

Using social media is a highly experiential task, therefore different emotions occur when people use them. The link of emotions with satisfaction is inherent and one may lead to the other, or vice versa [17]. Extant research has examined the role of emotions when using online services and how users' behavior is affected by their feelings $[4,6]$. Specifically in social media, affection has a positive effect on their usage [18], while the way people feel will have an influence on their satisfaction [19]. Some of the most widely studied emotions, such as enjoyment, have been found to increase users' satisfaction with online networks [7], and the majority of the studies in the area of online services either do not take into consideration emotions or focus on specific ones. However, emotions are a multidimensional factor and studying together positive and negative emotions, which are likely to coexist, may provide better understanding about their role on increasing satisfaction and formulation behaviors [5].

Positive emotions, like enjoyment and pleasure, and on the other hand, negative emotions, like anger and anxiety, were studied to explain users' satisfaction and behavior when using online services $[4,20]$. In detail, previous studies have found that positive emotions will increase users' satisfaction, while negative ones will decrease it [20]. Different types of emotions appear in social networks [21] and being able to capture, analyze, and explain them will lead to improved services [8], highlighting the need for a deeper understanding of their interactions with users' motivations on social media.

\subsection{Conceptual Model}

With the increasing number of people using social media, it is crucial to better understand users' different motivations to identify how their satisfaction can be increased [1, 9]. Recent studies in the area build on the UGT to explain users' motivations to use social media, and how they may differ from the motivations to use traditional media [2, 13]. Towards this end, various motivations have been identified as critical when using social media, with entertainment, information, social-psychological, and convenience among the most important ones, and their effect on users' attitudes and behavior has been verified $[2,10]$. However, their relationship with satisfaction needs to be explored 
further [1]. Also, since motivations are based on users' inner needs, the role of emotions should be examined [5]. As argued above, emotions are linked with user satisfaction, and their inclusion here will offer more insight on this relation and how it is shaped. However, there are not enough studies in the area examining motivations and emotions, and at the same time existing studies employ regression based tests, which assume a symmetric relation between the examined factors. Thus, further work needed to provide a general overview that describes the role of motivations and emotions, and their interrelations in predicting high satisfaction with social media.

To address this gap, we examine users' satisfaction with social mead by unravelling configurations of causally related sets of factors. We posit that there is a synergy among motivations and emotions in explaining satisfaction with social media, and theorize that there is not one single, optimal, configuration of such values. Instead, multiple and equally effective configurations of causal conditions exist, which may include different combinations of motivations and emotions. To conceptualize these relationships, we propose a conceptual model (Figure 1) showing the examined constructs and their intersections. Overlapping areas represent possible combinations among factors, that is areas that one factor may exist together with the rest (e.g., combinations that explain high satisfaction are included within the outcome of interest area).

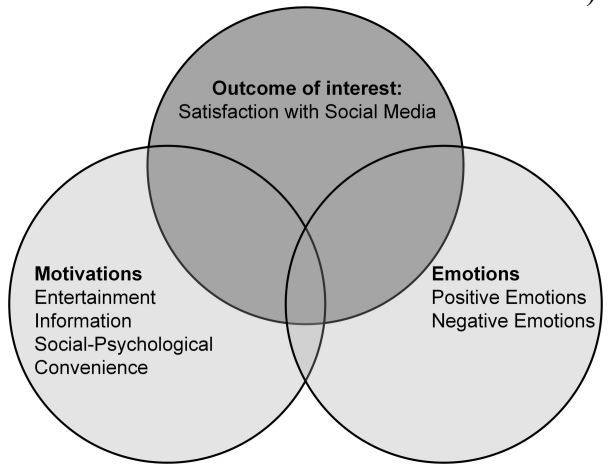

Fig. 1. Venn diagram of the conceptual model explaining satisfaction with social media

Drawing on complexity theory and the principle of equifinality, a result may be equally explained by alternative sets of causal conditions [22]. These conditions may be coalesced in sufficient configurations to explain the outcome [11,23]. Motivations and emotions are important antecedents of users' satisfaction $[1,17]$, thus they may interact with each other in various configurations. For example, users that seek information or entertainment are more likely to be satisfied with social media if the feel happy using them, while at the same time users' may still be satisfied if they felt negative emotions due to the lack of convenience, but they managed to find the information they were looking for. Thus, high satisfaction may be achieved through various ways.

Further, configuration theory proposes the principle of causal asymmetry, which means that the presence or absence of a condition that explains an outcome, depends on the presence or absence of the other conditions [23]. Following the previous example, alternative configurations may include (i) high levels of information and entertainment motivations, and positive emotions in one configuration, or (ii) high levels of 
negative emotions, low levels of convenience, and high levels of information motivations. Thus, the same outcome may be influenced either positively or negatively by a specific factor, depending on how it combines with the other factors.

\section{$3 \quad$ Research Methodology}

\subsection{Sampling and Measures}

Our research model deals with experienced users in social media. The respondents were given a definition of social media, followed by a few examples, and they were asked to keep this in mind, while answering the questions based on their previous experience. We used a sample of 582 Greek users of social media. They were kindly asked to voluntary fill in an online questionnaire with no reward for their participation. The survey was conducted in March-April 2016 and aimed at 1800 social media users. The sample consists of more women $(64 \%)$ than men $(36 \%)$. The majority of the responders are between $25-34$ years old (37\%), 27\% between $18-24$, followed by $19 \%$ at the age of 35 to 44 and $12 \%$ were less than 17 years old. The rest were over 45 years old (5\%). In terms of the educational status, the vast majority $(50,7 \%)$ were university graduates. Almost all of our sample had experience in social media for over a year.

The first part of the questionnaire has questions about the demographic profile of the responders, and the second part had measures of the constructs chosen to be examined, selected from the proper literature review (needs, performance, confirmation, emotions, satisfaction). For the questions of the second part, a 7-point Likert scale was used, anchored from 1 ("completely agree") to 7 ("completely disagree"). Motivations include four types of motivations and explain to why people use social media $[2,10]$. Positive and negative emotions, divided based on valence, refer to how users feel when using social media, and have been adopted from Scherer, Shuman, Fontaine and Soriano [24]. Satisfaction refers to users' overall satisfaction with social media [25]. In the Appendix a detailed table presents all constructs along with descriptives and loadings.

\subsection{FsQCA}

FsQCA is the combination of fuzzy sets and logic principles with Qualitative Comparative Analysis (QCA) [26]. It has been applied in many fields, like business and social commerce [5,27], and takes the researcher beyond the traditional MRAs as it identifies multiple paths explaining the same outcome. These paths are combinations of variables, and may include variables influencing the outcome only in a small subset of cases, that are not identified by MRAs [11]. The combinations create multiple solutions (or configurations) offered by fsQCA, and include both necessary and sufficient conditions, which may be present or absent on a solution, or they may be on a "do not care" situation. The "do not care" situation indicates that the factor may either be present or absent and it does not play a role on a specific configuration. Necessary and sufficient conditions may be present (or absent) as core, indicating a strong causal relationship with the outcome, and peripheral elements, indicating a weaker relationship [23]. 
Calibration follows, all factors are transformed into fuzzy-sets with a range of values from $0-1$ [12]. This may be done directly or indirectly, based on the data and underlying theory [12]. In the direct way, three qualitative thresholds (or breakpoints) are chosen, while in the indirect, the factors are calibrated following qualitative assessments. The thresholds set the full membership, full non-membership and intermediate membership, representing the degree that a case is part of a set [12]. We employ the direct method and the thresholds are chosen based on the survey scale; full membership threshold is set at 6; full non-membership threshold is set at 2; and, intermediate membership at 4 .

Next, fsQCA produces a truth table of $2^{k}$ rows $(k$ is the number of predictors and each row represents every possible combination), which is sorted based on frequency (i.e., the number of observations for each combination) and consistency (i.e., "the degree to which cases correspond to the set-theoretic relationships expressed in a solution") $[12,23]$. To obtain a minimum number of observations for the assessment of the relationships a frequency threshold is set. We set at 3 , and all combinations with smaller frequency are removed from further analysis $[12,23]$. Also, the threshold for consistency is set at over the recommended threshold of 0.85 [28]. The combinations above the consistency threshold are those that fully explain the outcome, which means that for those combinations the outcome variable is set at 1 , and for the rest is set at 0 . FsQCA offers three sets of solutions (i.e., complex, parsimonious, intermediate) that need to be interpreted by the researcher. The complex solution presents all combinations of conditions when logical operations are applied, and are simplified into parsimonious and intermediate solutions, as they are simpler to interpret.

\section{$4 \quad$ Findings}

\subsection{Measurements}

The constructs are assessed for reliability based on the Cronbach alpha and Composite Reliability indicators, that show acceptable indices of internal consistency as all constructs exceed the cut-off threshold of .70. For validity, the average variance extracted (AVE) needs to be larger than .50, correlations among variables should be lower than .80 points, and the square root of each factor's AVE should be higher than its correlations with the other factors [29]. The AVE ranges between 0.57 and 0.84 , all correlations are lower than 0.80 , and square root AVEs are larger than corresponding correlations. Since our data are not normally distributed, we employ Kendall's tau test to measure correlation, which is generally preferred over Spearman's rho, as it is a better estimate of the corresponding population parameter, and its standard error is known [30]. The findings are presented in Table 1. Multicollinearity [31] is examined along with the potential common method bias by utilizing the common latent factor technique and the CFA marker variable technique, which are better from other control procedures (e.g., Harman's single factor test) [32]. Variance inflation factor (VIF) for all factors is lower than the recommended value $(<3)$, thus multicollinearity is not an issue. Common method bias is not a problem, as variance from the common latent factor technique and the CFA marker variable technique, is 0.08 and 0.21 , respectively. 
Table 1. Descriptive statistics and correlations of latent variables

\begin{tabular}{|l|c|l|l|l|l|l|l|l|l|l|}
\hline Construct & $\begin{array}{c}\text { Mean } \\
\text { (S.D.) }\end{array}$ & CR & AVE & $\mathbf{1}$ & $\mathbf{2}$ & $\mathbf{3}$ & $\mathbf{4}$ & $\mathbf{5}$ & $\mathbf{6}$ & $\mathbf{7}$ \\
\hline $\begin{array}{l}\text { 1.Entertain- } \\
\text { ment }\end{array}$ & $\begin{array}{c}4.10 \\
(1.49)\end{array}$ & .82 & .53 & .73 & & & & & & \\
\hline 2. Information & $\begin{array}{c}4.64 \\
(1.57)\end{array}$ & .92 & .74 & .27 & .86 & & & & & \\
\hline $\begin{array}{l}3 . \text { Social Psy- } \\
\text { chological }\end{array}$ & $\begin{array}{c}3.11 \\
(1.22)\end{array}$ & .87 & .64 & .34 & .18 & .80 & & & & \\
\hline $\begin{array}{l}4 . \text { Conven- } \\
\text { ience }\end{array}$ & $\begin{array}{c}4.75 \\
(0.91)\end{array}$ & .91 & .70 & .39 & .33 & .45 & .84 & & & \\
\hline $\begin{array}{l}\text { 5.Positive } \\
\text { Emotions }\end{array}$ & $\begin{array}{c}3.51 \\
(1.38)\end{array}$ & .93 & .61 & .44 & .33 & .48 & .40 & .78 & & \\
\hline $\begin{array}{l}\text { 6.Negative } \\
\text { Emotions }\end{array}$ & $\begin{array}{c}2.16 \\
(1.64)\end{array}$ & .93 & .57 & -.02 & .04 & .14 & -.01 & .19 & .76 & \\
\hline $\begin{array}{l}\text { 7.Satisfaction } \\
4.44 \\
(1.64)\end{array}$ & .94 & .78 & .39 & .38 & .43 & .61 & .53 & -.14 & .89 \\
\hline
\end{tabular}

Note: Diagonal elements (in bold) are the square root of the average variance extracted (AVE). Off-diagonal elements are the correlations among constructs (all correlations higher than 0.1 are significant, $\mathrm{p}<$ 0.01 ;). For discriminant validity, diagonal elements should be larger than off-diagonal elements. CR; Composite Reliability.

\subsection{Findings from fsQCA}

The findings from the fsQCA on the configurations for high satisfaction when using social media are presented in Table 2. Each combination in the solution is able to explain the same outcome at a specific amount. In detail, the presence of a condition is presented by black circles $(\bullet)$, and its absence by crossed-out circles $(\otimes)$ [23]. Blank spaces indicate a "do not care" situation, which means that the condition may either be present or absent. Consistency values are presented in Table 2 for every and the overall solution, with all values being higher than the recommended threshold $(>0.75)$. Consistency shows the degree that a relationship has been approximated, and coverage evaluates the empirical relevance of a consistent subset [28]. The overall consistency is similar to the correlation and the overall solution coverage indicates the extent to which high satisfaction may be determined from the existing configurations, and is comparable to the R-square value reported in traditional regression analyses. The overall solution coverage of .80 indicates that a substantial amount of the outcome is explained by the eight solutions. FsQCA estimates also the empirical relevance for every solution, by calculating raw and unique coverage. The raw coverage describes the amount of the outcome that is explained by a certain alternative solution, while the unique coverage describes the amount of the outcome that is exclusively explained by a certain alternative solution. The solutions presented in Table 2 explain a great number of users' satisfaction with social media, ranging from $25 \%$ to $59 \%$ cases associated with the outcome. 
Table 2. Combinations that lead to high satisfaction when using social media

\begin{tabular}{|c|c|c|c|c|c|c|c|c|}
\hline & \multicolumn{8}{|c|}{ Solution } \\
\hline Configuration & 1 & 2 & 3 & 4 & 5 & 6 & 7 & 8 \\
\hline \multicolumn{9}{|l|}{ Motivation } \\
\hline Entertainment & $\bullet$ & & & O & O & & 0 & - \\
\hline Information & O & O & O & & O & & & $\bullet$ \\
\hline Social Psychological & & $\otimes$ & & $\otimes$ & $\otimes$ & $\otimes$ & $\bullet$ & $\otimes$ \\
\hline Convenience & 0 & O & 0 & O & & O & O & \\
\hline \multicolumn{9}{|l|}{ Emotions } \\
\hline Positive & & & $\otimes$ & $\otimes$ & $\otimes$ & $\otimes$ & & O \\
\hline Negative & & & $\otimes$ & & $\otimes$ & 0 & O & $\bullet$ \\
\hline Consistency & .92 & 0.89 & .93 & .91 & .93 & .86 & .95 & .95 \\
\hline Raw Coverage & .59 & 0.56 & .36 & .41 & .29 & .29 & .28 & .25 \\
\hline Unique Coverage & .05 & 0.03 & .02 & .03 & .01 & .01 & .02 & .01 \\
\hline \multicolumn{4}{|l|}{ Overall Solution Consistency } & \multicolumn{5}{|l|}{0.86} \\
\hline & \multicolumn{5}{|c|}{0.80} \\
\hline \multicolumn{9}{|c|}{$\begin{array}{l}\text { Note: Black circles }(\Theta) \text { indicate the presence of a condition, and circles with "x" }(\otimes) \text { indicate } \\
\text { its absence. Large circles indicate core conditions, and small ones represent peripheral condi- } \\
\text { tions. Blank spaces indicate "don't care." }\end{array}$} \\
\hline
\end{tabular}

Solutions 1-5 present combinations that lead to high satisfaction when using social media, when emotions are not high or not important. In detail, high information and convenience motivations will satisfy the users when (i) combined with high entertainment (Solution 1) or (ii) low social-psychological motivations (Solution 2), regardless of emotions, or (iii) when both positive and negative emotions are low (Solution 3). Next, the combination of high entertainment and convenience will lead to high satisfaction when social-psychological motivations are low, as well as emotions (Solutions 4 and 5). On the other hand, when one or both emotions are high, satisfaction may be achieved by (i) high convenience with low social-psychological motivations and positive emotions (Solution 6), (ii) high entertainment, convenience and social-psychological motivations (Solution 7), or last by (iii) high entertainment, information, with low social-psychological motivations (Solution 8).

\section{Discussion}

This study suggests that in social media, users' motivation and emotions combine and create configurations that explain their overall satisfaction with social media. We draw on complexity theory and configuration theory and propose a conceptual model to identify the aforementioned configurations. In detail, the model includes four users' motivations, that is entertainment, information, social psychological, convenience, and their positive and negative emotions. The findings lead to multiple recipes explaining high satisfaction with social media, with two main outcomes. First, we identify the importance of motivations when using social media over emotions, and second the ability of emotions to lead to satisfied users when motivations are less important for them. 
The findings show that convenience is the most important factor, since it is present (i.e., high) in 6 out of 8 solutions, always as a core factor. People tend to choose solutions that make their life easier, especially with the advancement in mobile devices, thus using social media because it is simple and easy will increase their satisfaction. Also, convenience is critical as it is linked with the other motivations, because it can make it easier or simpler to access information, seek entertainment, and communicate with others more efficiently. This is also verified by our findings, on which entertainment and information are present in 5 out of 8 solutions, except for social-psychological motivation which is mainly absent (i.e., low). The latter is explained by the relatively low level of responses of the users, as shown in the Appendix. However, this indicates that users do not actively seek to fulfil such needs when using social media, raising the question if the way people use social media has changed over the past 15 years.

As social media are both utilitarian and high experiential systems thus and much attention should be given to internal factors, our findings indicate that emotions and social-psychological factors are less important than entertainment, information, and convenience. Nonetheless, we identify specific patterns of users for whom these factors are important and influence greatly their satisfaction. This verifies the fact that people have different motivations when using social media and extends previous findings by highlight how motivations and emotions combine to lead to high satisfaction $[1,2]$.

This research has both theoretical and practical implications towards satisfaction with social media. First, it complements extant research in the area $[1,2]$ by offering an alternative view on how motivations and emotions combine with each other to predict high satisfaction. Second, we provide empirical support on how different levels of motivations and emotions may explain satisfaction of the users', a relation that has not been examined deeply in the past [1]. Finally, we extend the literature on social media by examining emotions as a multidimensional concept studying together positive and negative emotions, as they are likely to overlap and one may diminish the other [5]. Although emotions were found to be important in certain occasions in leading to satisfaction, we are not able to fully verify previous findings in the area of online services, that emotions to be critical in formulating users' attitude, satisfaction and behavior [1, $4,5]$, increasing the need for further studies into the area.

Following the results of this study, practitioners can gain insight on how their highly satisfied customers are motivated and how they feel. This can help them improve or revise their online strategies and business models, by optimizing the services they offer as they can choose the optimal mix of motivations and emotions to target their customers accordingly. Since new social media appear quite frequently, practitioners may exploit the identified paths to understand the rationale of users' decisions, and by extension focus on specific functionality or create more effective communication strategies, to satisfy users and increase adoption and use. For example, a new social media that has only built a mobile application should focus on convenience and either entertainment or information, depending on the services and functionality it supports.

This paper contributes to methodology, as it differs from previous studies in the area, employing regression-based analyses to examine users' motivations, satisfaction and behaviour. Here, a configuration analysis is performed with the use of fsQCA, to examine the asymmetric relationships among the factors. This methodology has recently 
received increased attention in online services and social media [9, 27, 33], and if applied together with complexity theory and configuration theory, can contribute to the creation of new hypotheses, models, and theories [11,22]. Thus, we propose a conceptual model to identify highly satisfied users of social media based on their motivations and emotions, and the findings show complex causal patterns among the variables and highlight asymmetric relationships that may lead to the same outcome (i.e., high satisfaction). Thus, future studies, should examine direct and indirect effects of motivations and emotions on users' satisfaction, and complement or extend our findings by contrasting findings from both fsQCA and regression-based analyses.

As with all empirical studies, there are some limitations. First, the sampling method may limit the generalization of the findings since snowball sampling was used to recruit respondents. Further, the findings are based on self-reported data. Future studies may combine self-reported data with real data from using social media, and extend them with semi-structured interviews, observations, which may provide deeper insight on user satisfaction. Also, here we only examine value motivations and emotions as antecedents of satisfaction. Researchers may include more variables that have been found to influence users' satisfaction as well as examine their effect on behaviour.

\section{References}

1. Kim, J.H., Kim, M.-S., Nam, Y.: An analysis of self-construals, motivations, Facebook use, and user satisfaction. Intl. Journal of Human-Computer Interaction 26, 1077-1099 (2010)

2. Kim, Y., Sohn, D., Choi, S.M.: Cultural difference in motivations for using social network sites: A comparative study of American and Korean college students. Computers in human behavior 27, 365-372 (2011)

3. Au, N., Ngai, E.W., Cheng, T.E.: Extending the understanding of end user information systems satisfaction formation: An equitable needs fulfillment model approach. MIS quarterly 43-66 (2008)

4. Pappas, I.O., Kourouthanassis, P.E., Giannakos, M.N., Chrissikopoulos, V.: Shiny happy people buying: the role of emotions on personalized e-shopping. Electronic Markets 24, $193-$ 206 (2014)

5. Pappas, I.O., Kourouthanassis, P.E., Giannakos, M.N., Chrissikopoulos, V.: Explaining online shopping behavior with fsQCA: The role of cognitive and affective perceptions. Journal of Business Research 69, 794-803 (2016)

6. Pappas, I.O., Kourouthanassis, P.E., Giannakos, M.N., Chrissikopoulos, V.: Sense and sensibility in personalized e-commerce: How emotions rebalance the purchase intentions of persuaded customers. Psychology \& Marketing (2017)

7. Kang, Y.S., Hong, S., Lee, H.: Exploring continued online service usage behavior: The roles of self-image congruity and regret. Computers in Human Behavior 25, 111-122 (2009)

8. García-Crespo, Á., Colomo-Palacios, R., Gómez-Berbís, J.M., Ruiz-Mezcua, B.: SEMO: a framework for customer social networks analysis based on semantics. Journal of Information Technology 25, 178-188 (2010)

9. Krishen, A.S., Berezan, O., Agarwal, S., Kachroo, P.: The generation of virtual needs: Recipes for satisfaction in social media networking. Journal of Business Research 69, 5248$5254(2016)$ 
10. Chung, J.Y., Buhalis, D.: Information needs in online social networks. Information Technology \& Tourism 10, 267-281 (2008)

11. Woodside, A.G.: Embrace perform • model: Complexity theory, contrarian case analysis, and multiple realities. Journal of Business Research 67, 2495-2503 (2014)

12. Ragin, C.C.: Redesigning social inquiry: Fuzzy sets and beyond. Wiley Online Library (2008)

13. Raacke, J., Bonds-Raacke, J.: MySpace and Facebook: Applying the uses and gratifications theory to exploring friend-networking sites. CyberPsychol. Behav. 11, 169-174 (2008)

14. Wang, Y., Fesenmaier, D.R.: Modeling participation in an online travel community. Journal of Travel Research 42, 261-270 (2004)

15. Lin, K.-Y., Lu, H.-P.: Why people use social networking sites: An empirical study integrating network externalities and motivation theory. Computers in Human Behavior 27, 1152-1161 (2011)

16. Shin, D.-H.: Analysis of online social networks: a cross-national study. Online Information Review 34, 473-495 (2010)

17. Oliver, R.L.: Satisfaction: A behavioral perspective on the consumer. Routledge (2014)

18. Xu, C., Ryan, S., Prybutok, V., Wen, C.: It is not for fun: An examination of social network site usage. Information \& Management 49, 210-217 (2012)

19. Chang, Y.P., Zhu, D.H.: The role of perceived social capital and flow experience in building users' continuance intention to social networking sites in China. Computers in Human Behavior 28, 995-1001 (2012)

20. Kuo, Y.-F., Wu, C.-M.: Satisfaction and post-purchase intentions with service recovery of online shopping websites: Perspectives on perceived justice and emotions. International Journal of Information Management 32, 127-138 (2012)

21. Van Zalk, N., Van Zalk, M., Kerr, M., Stattin, H.: Social anxiety as a basis for friendship selection and socialization in adolescents' social networks. Journal of Personality 79, 499$526(2011)$

22. Fiss, P.C.: A set-theoretic approach to organizational configurations. Academy of management review 32, 1180-1198 (2007)

23. Fiss, P.C.: Building better causal theories: A fuzzy set approach to typologies in organization research. Academy of Management Journal 54, 393-420 (2011)

24. Scherer, K.R., Shuman, V., Fontaine, J.R., Soriano, C.: The GRID meets the Wheel: Assessing emotional feeling via self-report. Components of emotional meaning: A sourcebook 281-298 (2013)

25. Lu, H.-P., Hsiao, K.-L.: The influence of extro/introversion on the intention to pay for social networking sites. Information \& Management 47, 150-157 (2010)

26. Ragin, C.C.: Fuzzy-set social science. University of Chicago Press (2000)

27. Mikalef, P., Pappas, I.O., Giannakos, M.: Consumer Intentions on Social Media: A fsQCA Analysis of Motivations. Conference on e-Business, e-Services and e-Society, pp. 371-386. Springer (2016)

28. Ragin, C.C.: Set relations in social research: Evaluating their consistency and coverage. Political Analysis 14, 291-310 (2006)

29. Fornell, C., Larcker, D.F.: Structural equation models with unobservable variables and measurement error: Algebra and statistics. J. Marketing Res. 382-388 (1981)

30. Howell, D.C.: Statistical methods for psychology. Cengage Learning (2012) 
31. O'brien, R.M.: A caution regarding rules of thumb for variance inflation factors. Quality \& Quantity 41, 673-690 (2007)

32. MacKenzie, S.B., Podsakoff, P.M.: Common method bias in marketing: causes, mechanisms, and procedural remedies. Journal of Retailing 88, 542-555 (2012)

33. Kourouthanassis, P.E., Mikalef, P., Pappas, I.O., Kostagiolas, P.: Explaining travellers online information satisfaction: A complexity theory approach on information needs, barriers, sources and personal characteristics. Information \& Management (2017)

\section{Appendix}

Scale items with mean, standard deviation and standardized loading

\begin{tabular}{|c|c|c|c|c|c|c|c|c|}
\hline \multicolumn{5}{|c|}{ Construct and scale items } & \multicolumn{2}{|c|}{ Mean } & S.D. & Loading \\
\hline \multicolumn{9}{|c|}{ Entertainment } \\
\hline \multicolumn{5}{|c|}{ I use social media to forget about work or other things } & \multicolumn{2}{|l|}{3.01} & 1.77 & 0.61 \\
\hline \multicolumn{5}{|c|}{ I use social media to relax } & \multicolumn{2}{|l|}{4.82} & 1.64 & 0.83 \\
\hline \multicolumn{5}{|c|}{ I use social media to feel excited. } & \multicolumn{2}{|l|}{3.37} & 1.56 & 0.75 \\
\hline \multicolumn{5}{|c|}{ I use social media to pass the time } & \multicolumn{2}{|l|}{5.18} & 1.62 & 0.70 \\
\hline \multicolumn{9}{|c|}{ Information } \\
\hline \multicolumn{5}{|c|}{ I use social media to learn about unknown things } & \multicolumn{2}{|l|}{4.94} & 1.57 & 0.88 \\
\hline \multicolumn{5}{|c|}{ I use social media to do research } & 4.00 & & 1.92 & 0.78 \\
\hline \multicolumn{5}{|c|}{ I use social media to learn about useful things } & 4.69 & & 1.68 & 0.92 \\
\hline I use social $n$ & t new id & & & & 4.93 & & 1.57 & 0.86 \\
\hline Social Psycl & & & & & & & & \\
\hline I use social $n$ & ek ident & & & & 2.39 & & 1.47 & 0.74 \\
\hline I use social n & ep relat & onship & with memb & & 4.26 & & 1.84 & 0.82 \\
\hline I use social n & ek a sen & e of b & longing & & 2.36 & & 1.52 & 0.78 \\
\hline I use social n & t involv & d wit & members & & 3.40 & & 1.75 & 0.86 \\
\hline Convenience & & & & & & & & \\
\hline I use social $\mathrm{n}$ & me, any & where & & & 4.01 & & 1.97 & 0.80 \\
\hline I use social $\mathrm{n}$ & eniently & & & & 5.01 & & 1.58 & 0.90 \\
\hline I use social $n$ & & & & & 5.41 & & 1.51 & 0.87 \\
\hline I use social $n$ & get what & I wan & for less effo & & 4.57 & & 1.74 & 0.79 \\
\hline Satisfaction & & & & & & & & \\
\hline I am satisfied & experien & ce of $t$ & sing social $n$ & dia & 4.66 & & 1.38 & 0.90 \\
\hline I am pleased & xperienc & e of u & ing social $\mathrm{m}$ & & 4.54 & & 1.35 & 0.91 \\
\hline My decision & al medi & was c & wise one & & 4.05 & & 1.50 & 0.83 \\
\hline My feeling $\mathrm{w}$ & ocial m & dia $w$ & s good & & 4.50 & & 1.39 & 0.90 \\
\hline Emotions & & & & & & & & \\
\hline & Mean & SD & Loading & & & Mean & SD & Loading \\
\hline Positive & & & & & & & & \\
\hline Pleasure & 4.13 & 1.64 & 0.88 & Contentment & & 3.69 & 1.70 & 0.87 \\
\hline Joy & 3.90 & 1.61 & 0.86 & Admiration & & 2.99 & 1.66 & 0.79 \\
\hline Pride & 2.49 & 1.57 & 0.73 & Love & & 2.69 & 1.64 & 0.75 \\
\hline Amusement & 4.63 & 1.55 & 0.77 & Relief & & 2.59 & 1.58 & 0.71 \\
\hline Interest & 4.44 & 1.46 & 0.66 & & & & & \\
\hline Negative & & & & & & & & \\
\hline Anger & 2.42 & 1.58 & 0.78 & Disappointment & & 2.87 & 1.89 & 0.81 \\
\hline Hate & 1.80 & 1.32 & 0.77 & Shame & & 2.08 & 1.56 & 0.80 \\
\hline Contempt & 2.31 & 1.63 & 0.76 & Regret & & 1.87 & 1.35 & 0.68 \\
\hline Disgust & 2.27 & 1.65 & 0.86 & Guilt & & 1.71 & 1.27 & 0.62 \\
\hline Fear & 1.95 & 1.44 & 0.67 & Sadness & & 2.30 & 1.63 & 0.80 \\
\hline & & & & Compassion & & 2.71 & 1.67 & 0.69 \\
\hline
\end{tabular}

